\title{
Siphons, Water Clocks, Cooling Coffee, and Leaking Capacitors: Classroom Activities and a few Equations to Help Students Understand Radioactive Decay and Other Exponential Processes
}

\author{
John B. Brady \\ Department of Geology, Smith College, Northampton, MA 01063 \\ jbrady@science.smith.edu
}

\begin{abstract}
Although an understanding of radiometric dating is central to the preparation of every geologist, many students struggle with the concepts and mathematics of radioactive decay. Physical demonstrations and hands-on experiments can be used to good effect in addressing this teaching conundrum. Water, heat, and electrons all move or flow in response to generalized forces (gradients in pressure, temperature, and electrical potential) that may change because of the flow. Changes due to these flows are easy to monitor over time during simple experiments in the classroom. Some of these experiments can be modeled as exponential decay, analogous to the mathematics of radioactive decay, and can be used to help students visualize and understand exponential change. Other, similar experiments produce decay or change that is not exponential. By having classes, in small groups, conduct several experiments involving flows, a learning synergy can be encouraged in which the physical and mathematical similarities of flow processes are emphasized. For the best results, students should be asked to analyze the experimental data, using graphs and algebra or calculus as appropriate to the class, to determine the nature of the decay process and to make predictions, either forward or backward in time as would be done for radiometric dating. Basic quantitative skills are strengthened or developed as part of these activities. Encountering a number of important geologic processes in the same mathematical context provides a good introduction for further study of any one of them.
\end{abstract}

Keywords: Teaching, geologic time, quantitative skills, experiments, clepsydra 


\section{Introduction}

Radiometric dating provides essential data for much of our geologic understanding of earth history and, therefore, is an important topic for many courses in geology. Because calculus is typically used in developing the mathematics of radioactive decay, students without calculus are likely to have difficulty in grasping some of the principles of radiometric dating and in applying the relevant equations. The significance of radioactivity, exponential decay, and radiometric dating to geologists, chemists, and physicists and the challenges of teaching about these topics have led to numerous published pedagogic strategies. These include stochastic experiments with coins (Kowalski, 1981; Tyburczy, 2000; Wenner, 2008a), dice (Celnikier, 1980; Priest, and Poth, 1983; Schultz, 1987; Benimoff, 1999), poker chips (McGeachy, 1988), M\&M's (AAAS Science Netlinks, 2001a; Gardner et al., 2005; Wenner, 2008b), or popcorn (Wenner, 2008c), measurements of actual radioactive decay (Jones, 1957; Whyte and Taylor, 1962; Supon and Kraushaar, 1983), analog experiments (Bohn and Nadig, 1938; Knauss, 1954; Smithson and Pinkston, 1960; Wunderlich and Peastrel, 1978; Wise, 1990; AAAS Science Netlinks, 2001b; Greenslade, 2002; Fairman et al., 2003; Sunderman, 2007), and general mathematical approaches or advice (Guenther, 1958; Vacher, 2000; Shea, 2001; Huestis, 2002). I have tried a number of classroom activities to help students understand the mathematics of radioactive decay, and describe here some of the more successful experiments that I believe are useful for geology classes. I will also argue that having classes do several of the experiments, simultaneously in small groups, demonstrates the mathematical connectedness of a variety of important geologic processes. Furthermore, the data collection and analysis skills learned by studying any one of the processes help build a quantitative literacy that can be transferred and applied to the other processes.

\section{A Siphon Experiment}

My most-used decay experiments involve flowing water, and can be done with a "U-tube" or a siphon. Geologists think a lot about flowing water. Streams, erosion, groundwater, and flooding 
are topics in introductory and advanced geology courses, and some of the principles of flowing water are familiar to even beginning students. I find that most geology students are able to make good predictions when presented with the experimental design shown in Figure 1. The "U-tube" apparatus consists of two vertical plastic tubes ( $44.5 \mathrm{~mm}$ i.d.) connected at their bases by a copper pipe (12.7 mm i.d.) and valve. The valve is designed so that it can be opened quickly to a preset position against a setscrew (see inset in Figure 1). What will happen if the tube on the left is filled with water to the height $\mathbf{h}_{\mathbf{L}}$, the tube on the right is filled with water to the height $\mathbf{h}_{\mathbf{R}}$, and the valve is opened? All students predict correctly that water will flow from the mostly full tube to the mostly empty tube through the connecting pipe until the water level in the two tubes is equal. And if asked, many students will predict that the flow will slow down as the difference in water heights $\left(\mathbf{h}_{\mathbf{L}}-\mathbf{h}_{\mathbf{R}}\right)$ decreases. Their intuition, based on previous experiences, tells them (or will let them be easily convinced) that the flow rate is proportional to the difference in heights, analogous to hydrologic head $\left(\mathbf{H}=\mathbf{h}_{\mathbf{L}}-\mathbf{h}_{\mathbf{R}}\right)$ :

$$
\text { Water Flow }=\mathbf{- \mathbf { k } _ { \mathbf { 1 } }} \cdot \mathbf{H}
$$

where $\mathbf{k}_{\mathbf{1}}$ is a constant. (The minus sign is used here to anticipate other flow equations where a coordinate system is used. The subscript $\mathbf{1}$ in the constant $\mathbf{k}_{\mathbf{1}}$ is used to differentiate $\mathbf{k}_{\mathbf{1}}$ from the other constants $\mathbf{k}_{\mathbf{i}}$ used in this paper.)

The plastic tubes are cylinders, so the volume of water flow is proportional to the change in head (dH). Replacing "Water Flow" by dH/dt, equation (1) becomes

$$
\mathbf{d H} / \mathbf{d t}=-\mathbf{k}_{2} \cdot \mathbf{H},
$$

which is an exponential decay equation. The constant $\mathbf{k}_{\mathbf{2}}$ in (2) is related to the constant $\mathbf{k}_{\mathbf{1}}$ in (1), but incorporate the volume to height conversion. Because of its mathematical similarity, the change in $\mathbf{H}$ with time is a visual analog for the change in parent (or daughter) isotopes during radioactive decay. During the experiment, the height of the water in either tube can be seen to change quickly at first, then more and more slowly as the water heights in the two tubes 
approach one another. A little food coloring makes the water easier to see. Note that $\mathbf{d h} \mathbf{h}_{\mathbf{L}}=\mathbf{-} \mathbf{- d h} \mathbf{h}_{\mathbf{R}}$, so that

$$
\mathrm{dH} / \mathrm{dt}=2 \mathrm{dh} / \mathrm{dt}=-2 \mathrm{dh} / \mathrm{dt}=-\mathrm{k}_{2} \cdot \mathrm{H} .
$$

I have used this experiment both as a demonstration in front of a large audience and as an experiment for a small group in a lab setting. By adjusting the valve opening, the complete experiment can be done in less than two minutes, or over a longer time period to allow for careful data collection of water heights as a function of time. Although the U-tube apparatus in Figure 1 is not difficult to build, the experiment can be done with minimal preparation by using two large graduated cylinders joined by a clear plastic siphon tube. I used the siphon setup for several years before building the Figure 1 U-tube device for convenience, so I will always think of this as a siphon experiment. And after discovering the papers by Knauss (1954) and Smithson and Pinkston (1960), I have started using a siphon setup again for student data collection, as I will explain shortly.

How much mathematical detail I use and whether I have students collect data on the change in water height with time depends on my class and goals. In most cases, I present the U-tube apparatus with one tube full of colored water, discuss with the class their predictions about the consequences of opening the valve, and then proceed with a short experiment. I then develop the mathematics of exponential decay, beginning with an algebraic derivation of the decay equations that doesn't involve calculus (see Appendix). The recursive character of the algebraic approach is well suited for adapting to a spreadsheet model and graph, with each line representing one unit of time (e.g. one half-life). Students in some settings can be asked to do this as an exercise, during or between classes, or by the instructor using a computer and projector. After obtaining the decay equation (28), I then show the calculus derivation for those students who have had calculus. With an exponential decay equation in hand, I may revisit and perhaps rerun the Utube (or siphon) experiment. The concept of a half-life is very useful here and transfers directly to the visual demonstration involving water heights. 
I typically have my students collect their own data on water height as a function of time for the U-tube or siphon setup, either as a whole class experiment or as a small-group lab assignment. My preferred approach is to have each small group collect data on a different process or experimental setup, such as various water flow designs, cooling objects, or capacitor discharge. I describe some of these other experiments later in this paper. Most are exponential decay experiments, but some are not and serve to demonstrate the power of data analysis. The assignment includes a lab report that must include (1) a presentation of the data in graphical as well as tabular form, (2) a calculation of half-life and $\lambda$ (see Appendix) for their experiment, and (3) an evaluation of uncertainty in their measurements and calculations.

Data from a typical 10-minute-long U-tube experiment using the Figure 1 apparatus are shown in Figure 2. Shown also in Figure 2 is a solid line graphing exponential decay for equation (28) using a value of $\lambda$ taken from the first half-life observed (the time required to reduce $\mathbf{H}$ to onehalf its starting value). Similar results are obtained for a siphon experiment using $6 \mathrm{~mm}$ i.d. plastic siphon tube with a clamp to adjust flow rate. Note that the time required to equalize the water levels in the two tubes is less than predicted by the first half-life. Interestingly, the observed half-lives get shorter and shorter during the experiment. Although some choices of $\lambda$ fit the data better than the value from the first half-life, there is no single value of $\lambda$ that will describe an exponential decay that matches all the data. This discrepancy can be ignored by using an average value of $\lambda$, or it can used as a point of discussion and perhaps further experiments. A plausible explanation for the changing half-life length is that the resistance to flow of the water is greater when the water velocity is higher. This hypothesis can be tested by reducing the U-tube flow rate with the connecting valve (or by pinching the siphon tube with a clamp). Results of longer experiments are shown in Figure 3. To aid in comparison, the data have been normalized by dividing the $\mathbf{H}$ values by $\mathbf{H}_{\mathbf{0}}$ and the time values by the observed first half-life. Results from slower experiments do indeed more closely approximate the exponential 
decay equation, supporting the notion that resistance due to turbulence in the valve is responsible for the observed decrease half-life as $\mathbf{H}$ decreases.

Smithson and Pinkston (1960), following Knauss (1954), present a hydrodynamic design that yields good exponential decay data using a tall vertical tube and a 1.25-meter-long capillary tube drain, making the flow slow enough to be viscosity-controlled and follow Poiseuille's Law (see also Skinner, 1971). Their results encouraged me to try a 1.25-meter-long capillary-sized (2 mm i.d.) plastic siphon tube, instead of the larger (6 mm i.d.) tubing I had been using. Data from a siphon experiment with the $2 \mathrm{~mm}$ i.d. siphon are shown on a semi-log graph in Figure 4, along with some of the U-tube data of Figure 3. If $\ln \left(\mathbf{H} / \mathbf{H}_{\mathbf{0}}\right)$ is plotted vs. time $\mathbf{t}$, exponential decay data should fall along a straight line with slope $-\lambda$ (see equation A12). The siphon data fall nicely along the exponential decay line in Figure 4, showing the advantage of the small tubing size and absence of a constriction. A drawback is the length of the experiment, but this can be mitigated by using smaller i.d. vertical tubes or by collecting only part of the data, which would still permit an evaluation of $\boldsymbol{\lambda}$. Because of the variability of the siphon start, results are better if you get the siphon flowing before recording the starting value of $\mathbf{H}\left(=\mathbf{H}_{0}\right)$ for your data set.

A related experimental option also may be available if someone in your department studies groundwater. A common tool for laboratory measurement of hydraulic conductivity is a permeameter, which may be used in a constant-head in or a falling-head geometry (Fetter, 2001). A falling-head experiment is similar to the Smithson and Pinkston (1960) experiment, but with a soil sample replacing the capillary tube in the role of slowing the flow and keeping it in the lamellar flow regime. Some effort and experimentation is needed to find a soil sample that has a low enough permeability to allow precise measurement of head height as a function of time. However, a falling-head permeameter will also yield good exponential decay data and its use makes a very direct connection for students of the utility of the mathematics for hydrologic studies. 


\section{Water Clocks}

In many respects, the U-tube and siphon experimental apparatus described here can be considered water clocks: flowing water leads to a change in the water level that varies systematically with time. However, the exponential decay character of the siphon water clock would have been inconvenient for those wishing to track time in the ancient world. Water clocks were used by Egyptians at least 3500 years ago and by other ancient cultures including those in Greece (where they were called clepsydras, which means "water thief"), the Middle East, and China (Sloley, 1931; Barnett, 1998). Many students will have learned about water clocks in other contexts and may have questions concerning the relationship of the siphon experiment to ancient water clocks. Indeed, some students may have previously constructed a water clock, as there are many sources describing water clock experiments for elementary and middle school students (e.g. Zubrowski, 1988; Grossman et al., 2000; National Geographic Kids, 2008). I recommend capitalizing on this previous connection and including water clocks as one of the options for small group experiments. For some classes, it may even be a good strategy to begin with traditional water clocks and to discover or confront the behavior of the "siphon clock." For these reasons, I describe here the interesting quantitative features of several simple water clocks.

Ancient water clocks came in many designs, but most were based on water dripping or squirting out of a hole in the bottom or side of a vessel, some with the flow collected in another vessel (see Figure 5 for some water clock designs). Time was measured by the drop in the water level of the draining vessel or by the rise in the water level of the collection vessel. Although the rate of flow out of the ancient water clocks does depend on the level of water in the draining vessel, it turns out that drainage does not lead to an exponential decay of the water level.

Water draining from a cylindrical tank with a hole in the bottom follows Torricelli's Law (Mills, 1982; Groetsch, 1993), named for the mathematician Evangelista Torricelli who lived in Italy in the $17^{\text {th }}$ century. The kinetic energy of the squirting water changes the flow dynamics and must 
be accounted for in the mathematical description. Torricelli's Law states that the flow will be proportional to the square root of the water level:

$$
\left(\frac{d V}{d t}\right)=\left(-\mathrm{k}_{3}\right) \sqrt{\mathrm{h}},
$$

where $\mathbf{V}$ is the volume and $\mathbf{h}$ is the height of water in the tank, $\mathbf{t}$ is time, and $\mathbf{k}_{\mathbf{3}}$ is a constant. Equation (4) can be derived from Bernoulli's equation for energy balance in an incompressible liquid (Ansaldo, 1982; Fetter, 2001, p.115). Because $\mathbf{V}=\mathbf{h}\left(\boldsymbol{\pi} \mathbf{r}^{2}\right)$ for a cylinder of radius $\mathbf{r}$, we can replace $\mathbf{V}$ with $\mathbf{h}$ in equation (4) and constant $\mathbf{k}_{\mathbf{3}}$ with constant $\mathbf{k}_{\mathbf{4}}=\mathbf{k}_{\mathbf{3}} /\left(\boldsymbol{\pi} \mathbf{r}^{\mathbf{2}}\right)$ to yield:

$$
\left(\frac{\mathrm{dh}}{\mathrm{dt}}\right)=\left(\frac{-\mathrm{k}_{3}}{\pi \mathrm{r}^{2}}\right) \sqrt{\mathrm{h}}=\left(-\mathrm{k}_{4}\right) \sqrt{\mathrm{h}} .
$$

Integration of (5) yields an expression for the water level in the cylindrical tank as a function of time:

$$
h=\frac{\left(2-k_{4} \cdot t\right)^{2}}{4}
$$

assuming that $\mathbf{h}=\mathbf{1}$ at $\mathbf{t}=\mathbf{0}$. The interested reader can verify this result by differentiating (6) with respect to $\mathbf{t}$ and comparing the result with (5), using (6) to get the value of $\sqrt{\mathrm{h}}$. A graph of equation (6) is shown in Figure 6, along with an exponential decay graph for a process with the same first half-life. See also Farmer and Gass (1992) and Driver (1998).

It is apparent from Figure 6 that the variation of water level in a cylindrical water clock is not much improvement (if any!) on the siphon water clock, if a linear variation with time is sought. One solution to this problem was to keep the water level constant in the dripping vessel by constantly supplying water, adding an overflow, and measuring time from the level of water in a cylindrical collection vessel. A more common and simpler solution was to build water clocks with sloping sides, in effect replacing the cylinder with a cone. This makes sense because more 
water must flow from the vessel when the cone is full and the flow rate is highest. But does the water level in a cone-shaped water clock vary linearly with time? Does the cone angle matter?

For a cone, the volume $\mathbf{V}$ is related to the height $\mathbf{h}$ and the half-angle $\phi$ by

$$
V=\frac{\pi}{3}\left(\tan ^{2} \phi\right) \mathrm{h}^{3}
$$

Differentiating (7) with respect to $\mathbf{h}$ and using (4) we find:

$$
\left(\frac{d h}{d t}\right)=\left(\frac{d h}{d V}\right)\left(\frac{d V}{d t}\right)=\frac{\left(-\mathrm{k}_{3}\right) \sqrt{\mathrm{h}}}{\pi\left(\tan ^{2} \phi\right) h^{2}} .
$$

Solving (8) for a cone-shaped, dripping water clock with an initial water depth of one $(\mathbf{h}=\mathbf{1}$ for $\mathbf{t}=\mathbf{0})$ gives the expression for the water height $\mathbf{h}$ as a function of time $\mathbf{t}$ :

$$
h=\left(1-\frac{5 \mathrm{k}_{3} \mathrm{t}}{2 \pi\left(\tan ^{2} \phi\right)}\right)^{2 / 5} .
$$

This equation is plotted in Figure 7 for two cones of different half-angles $\phi$, along with a graph of $\mathbf{h}$ for a cylinder, choosing values of $\mathbf{k}_{\mathbf{3}}$ so that each vessel drains completely in the same time period. Cones with larger cone angles hold more water for the same height, so the flow rate and therefore the value of $\mathbf{k}_{\mathbf{3}}$ must be greater to drain in the same time as a cone with a smaller cone angle. Note, however, that the normalized result is independent of the cone half-angle! Interestingly, the variation of water level $\mathbf{h}$ with time for the cone water clock is not much improvement (if any!) on the cylindrical water clock or the siphon clock.

The real value of the cone shape for a water clock derives from the fact that the flow rate (dV/dt) is nearly independent of time. Substituting for $\mathbf{h}$ using (9) in equation (7), keeping the initial water depth of one $(\mathbf{h}=\mathbf{1}$ for $\mathbf{t}=\mathbf{0}), \mathbf{V}$ is given by: 


$$
V=\frac{\left(2 \pi-5 \mathrm{k}_{3} \mathrm{t} \cot ^{2} \phi\right)^{6 / 5} \tan ^{2} \phi}{6(2 \pi)^{1 / 5}} .
$$

Equation (10) is plotted in Figure 8, where the volume fraction of water $\mathbf{V} / \mathbf{V}_{\mathbf{0}}$ that has dripped from a conical water clock is shown as a function of time $\left(\mathbf{V}_{\mathbf{0}}\right.$ is the initial volume of water in the cone). The volume of water dripped from a cylindrical water clock is shown for comparison. It is evident from Figure 8 that the rate that water that drips from a cone-shaped vessel is very nearly constant with time, so the rise of the level of water in a cylindrical collection vessel is steady and makes a reasonable clock.

In spite of this good result for two-vessel, cone-shaped water clocks, many examples of onevessel water clocks are known. These have sloping sides, but are only the top part of a cone with a flat bottom and the shape of a modern bucket (see Figure 5C). I was unable to obtain an analytical solution for the water level $\mathbf{h}$ as a function of time $\mathbf{t}$ for a "bucket" water clock, but numerical solutions can be obtained with a spreadsheet using equations (4) and (6). Results for $\mathbf{h}$ and $\mathbf{V}$ over time from the numerical tests of "bucket" water clocks are shown in Figures 9 and 10. Data are shown for "buckets" with bottoms at $\mathbf{h}=\mathbf{0 . 2}, \mathbf{0 . 5}$, and $\mathbf{0 . 8}$ relative to a full cone height of $\mathbf{1}$. Buckets with a bottom at $\mathbf{h}=\mathbf{0 . 2}$ are nearly a full cone and give results similar to cone-shaped water clocks. Buckets with a bottom at $\mathbf{h}=\mathbf{0 . 8}$ are more like a cylinder and give results similar to a cylindrical water clock. Interestingly, buckets with a bottom at $\mathbf{h}=\mathbf{0 . 5}$ balance the features of a cone and a cylinder to create a water clock that has a nearly linear variation of $\mathbf{h}$ with time. The $\mathbf{h}=\mathbf{0 . 5}$ bucket clock is very close to the shape of a water clock in the Cairo Museum that dates to the reign of King Amenhotep III (1415-1380 BC) (Science Museum, 2008). Was this the result of a lucky guess? Good mathematical analysis? Or many experiments?

Water clocks can be made from vessels of most any shape, with a decay/draining behavior that reflects the shape. You can provide your students with vessels to use, or you can let them find 
their own. Funnels can be used for cone-shaped water clocks, but the size of the hole in the bottom will need to be reduced by a plug, which can be a cork or even chewing gum. Vessels for bucket water clocks with a $\mathbf{0 . 5}$ bottom height are not easy to find; most common containers have a bottom height over $\mathbf{0 . 6}$. A plastic funnel can be used as a "bucket" by plugging the bottom and drilling a drain hole at the desired bucket bottom height. When you find a vessel you want to use, start with a small drainage hole, enlarging it if you need to increase the drainage rate. Depending on the container, you may be able to have multiple drain holes with plugs in, or duct tape over, the ones not in use. An excellent discussion of various water clock designs and results of some experiments to test "linear outflow clepsydra" can be found in Mills (1982).

\section{Cooling Coffee}

Heat transfer is another process that can be described by the mathematics of exponential decay. The flow of heat by conduction between an object (such as a cup of coffee) and its surroundings is proportional to the difference in temperature $\left(\mathbf{T}-\mathbf{T}_{\mathbf{S}}\right)$

$$
\text { Heat Flow }=-\mathbf{k}_{\mathbf{5}} \cdot\left(\mathbf{T}-\mathbf{T}_{\mathbf{S}}\right),
$$

where $\mathbf{T}$ is the temperature of the object, $\mathbf{T}_{\mathbf{S}}$ is the temperature of the surroundings, and $\mathbf{k}_{\mathbf{5}}$ is a constant (Fourier's Law). If the object and its surroundings are "well stirred" or the heat flow within the object and within the surroundings is rapid relative to the heat transfer between them, the gain or loss of heat leads to a change in temperature of the object that depends on the heat capacity of the object. The resulting change in temperature $\mathbf{d T / d t}$, is directly related to the heat flow (11) so that:

$$
\mathbf{d T} / \mathbf{d t}=-\mathrm{k}_{\mathbf{6}} \cdot\left(\mathrm{T}-\mathrm{T}_{\mathrm{S}}\right),
$$

which is an exponential decay equation. The constant $\mathbf{k}_{\mathbf{6}}$ in (12) is related to the constant $\mathbf{k}_{\mathbf{5}}$ in (11) with heat capacity and surface area terms added. Because many students will have had experience with cooling coffee or tea or cocoa, measurement of temperature as a function of time for coffee is another good small group experiment to include in your decay mix. 
Many physicists, mathematicians, and engineers have used cooling coffee in their teaching, and a detailed analysis can be quite complicated (e.g. Walker, 1977; Dennis, 1980; Rees, 1988). Of particular interest has been the question of when to add cream if one wishes to speed the cooling of the coffee to drinking temperature (e.g. Greenslade, 1994; Smith, 2008). I have found cooling coffee to work well as an exponential decay experiment, in spite of these complications. We fill a paper cup with hot water (or coffee or tea), cover it with a lid (sealing the original holes if any), then insert a thermometer through a new hole in the center of the lid using a rubber stopper on the thermometer to preset the insertion length. The lid not only holds the thermometer, but it also prevents evaporation of the hot water and the attendant heat loss, which is significant. Figure 11 shows normalized cooling curves for covered and uncovered paper cups. The uncovered cup loses heat more rapidly at higher temperatures, principally because of evaporation. Covered or not, the paper cups lose heat less rapidly at lower temperatures than predicted by exponential decay based on the first half-life. This may be due to less vigorous convection in the colder water, which could make the water temperature less homogeneous. The cooling half-life of a 12-ounce (400 $\mathrm{ml}$ when completely full), covered paper cup is over 50 minutes, so data gathering limited to an hour will yield a result that is close to exponential decay. Ceramic mugs have cooling half-lives similar to paper cups of the same volume.

An alternative simple cooling experiment that yields more nearly ideal exponential decay data over several half-lives was described by Dewdney (1959). He used metal cylinders with a hole drilled in the center of the end that was large enough to insert a glass thermometer to the middle of the cylinder. I have tried this with a $38.1 \mathrm{~mm}$ o.d. aluminum cylinder, $76.2 \mathrm{~mm}$ long with a $6.6 \mathrm{~mm}$ diameter axial hole for our red-liquid, glass thermometers. This cylinder has a cooling half-life of 20 minutes and is very easy to use. Because the thermal conductivity of aluminum is high relative to the rate of heat loss to the surrounding air, the "well-stirred" boundary conditions are satisfied until the temperature approaches room temperature. 


\section{Capacitor Discharge}

Perhaps the most ideal analog experiment for exponential decay is to measure the charge on a capacitor as it discharges through a resistor. This experiment does not provide the visual display that accompanies the siphon experiment (unless you add a light bulb to the circuit), or the familiarity of cooling coffee. Nevertheless, the experiment is easy to set up and you can design a layout that meets your half-life needs. The current $\mathbf{I}$ (ampere $=$ coulombs/s) in a simple dccircuit consisting of a capacitor and a resistor (see Figure 12) obeys Ohm's law

$$
\mathbf{I}=\mathbf{V} / \mathbf{R},
$$

where $\mathbf{R}$ is the resistance (ohms) and $\mathbf{V}$ is the voltage (volts). The voltage $\mathbf{V}$ of a charged capacitor is given by the charge $\mathbf{Q}$ (coulombs) divided by the capacitance $\mathbf{C}$ (farad = coulomb/volt), and the current $\mathbf{I}$ is equal to the change of charge with time $\mathbf{d Q} / \mathbf{d t}$. Substituting in (13) we have

$$
\frac{\mathrm{dQ}}{\mathrm{dt}}=-\left(\frac{1}{\mathrm{C} \cdot \mathrm{R}}\right) \mathrm{Q}
$$

which has the same mathematical form as equations (2) and (12). As you can see in (14), the decay constant $\lambda$ is given by $\mathbf{1} /(\mathbf{C} \cdot \mathbf{R})$ and must have units of seconds ${ }^{-1}$. Therefore, the half-life $\ln (2) / \lambda$ of the capacitor discharge is the product of $(\mathbf{C} \cdot \mathbf{R})$ and $\ln (2)$. If you use a $200 \mathrm{ohm}$ resistor and a 5 volt, 1 farad capacitor, $\mathbf{C} \cdot \mathbf{R}=200$ seconds, $\ln (\mathbf{2})=0.693$, and the half-life is 139 seconds. Longer or shorter half-lives can be selected by changing the resistor or capacitor.

The capacitor can be charged with two 1.5 volt batteries in series. Charge $\mathbf{Q}$ of the capacitor is monitored during decay by measuring the voltage across it with a multimeter. Even with the purchase of a multimeter, the whole setup costs only about $\$ 60$ - or you can probably find all the parts in your local physics department. The results are so good that in a plot of voltage vs. time, the data are indistinguishable from an exponential curve. 


\section{Algebraic Equations for Radioactive Decay}

Students who understand algebra, but have not had calculus, need not be disadvantaged by the mathematics of exponential decay. In addition to the analog experiments described in this paper, for many years I have used an algebraic derivation of the equations used for radioactive dating. Even students who have had calculus tell me that they find this approach helpful. The derivation is based on a simple recursive formula that is developed as a discrete dynamical system, and is well-suited to a spread-sheet. The recursion strategy used here is very similar to many published explanations of compound interest, and the comparison of compounding annually, monthly, daily, etc. (e.g. Pierce, 2007; Moneychimp, 2008). The following text is a formal presentation of the algebraic equations, which I use as the basis for a class handout.

We begin with the experimental observation that the number of radioactive atoms of one isotope that decay in one unit of time is directly proportional to the number of radioactive atoms present. This means that the fraction $(\mathbf{k})$ of radioactive atoms of one isotope remaining after the passage of one unit of time of length $\mathbf{t}_{\mathbf{k}}$ (e.g. one hundred years) will be a unique value (k) that depends only on the isotope $\left(\left(\operatorname{such}\right.\right.$ as $\left.{ }^{40} \mathrm{~K}\right)$ and the length of the unit of time $\left(\mathbf{t}_{\mathbf{k}}\right)$. In our analysis, this observation is expressed as a recursive formula, generalized, and then solved for the total time (t) that has passed since the start of the decay process.

Let $\mathbf{P}_{\mathbf{0}}$ be the initial number of radioactive atoms ("parents") in a sample.

Let $\mathbf{k}$ be the fraction of radioactive atoms remaining after one unit of time.

Let $\mathbf{t}_{\mathbf{k}}$ be the length of the one unit of time.

Let $\mathbf{P}_{\mathbf{n}}$ be the number of radioactive atoms ("parents") remaining in the sample after $\mathbf{n}$ units of time, where $\mathbf{n}$ is an integer.

After one unit of time, the number $\left(\mathbf{P}_{1}\right)$ of parents remaining is:

$$
\mathrm{P}_{1}=\mathrm{P}_{0} \cdot \mathrm{k}
$$


After two units of time, the number $\left(\mathbf{P}_{2}\right)$ of parents remaining is:

$$
\mathrm{P}_{2}=\mathrm{P}_{1} \cdot \mathrm{k}
$$

Substituting for $\mathbf{P}_{\mathbf{1}}$ from the first equation we have:

$$
\mathrm{P}_{2}=\left(\mathrm{P}_{0} \cdot \mathrm{k}\right) \cdot \mathrm{k}=\mathrm{P}_{0} \cdot \mathrm{k}^{2}
$$

After three units of time, the number $\left(\mathbf{P}_{3}\right)$ of parents remaining is:

$$
\mathrm{P}_{3}=\mathrm{P}_{2} \cdot \mathrm{k}
$$

which becomes upon substitution for $\mathbf{P}_{\mathbf{2}}$ from equation (17):

$$
\mathrm{P}_{3}=\left(\mathrm{P}_{0} \cdot \mathrm{k}^{2}\right) \cdot \mathrm{k}=\mathrm{P}_{0} \cdot \mathrm{k}^{3} \text {. }
$$

By continuing this procedure, we can show that after $\mathbf{n}$ units of time $\left(\mathbf{t}_{\mathbf{k}}\right)$ the number of parents remaining is:

$$
\mathrm{P}_{\mathrm{n}}=\mathrm{P}_{0} \cdot \mathrm{k}^{\mathrm{n}}
$$

This equation expresses the fact that at any time the number of parents remaining is related in a simple way to the initial number of parent atoms. For example, if we select our unit of time $\mathbf{t}_{\mathbf{k}}$ so that $k=(\mathbf{1 / 2})$, then one-half of the parents will remain after one unit of time. This unit of time, $\mathbf{t}_{1 / 2}$, which is different for each radioactive isotope, is called the half-life of an isotope. Using (20), we can see that after 4 half-lives (i.e. 4 units of time), the number of parents remaining is:

$$
\mathrm{P}_{4}=\mathrm{P}_{0} \cdot\left(\frac{1}{2}\right)^{4}=\mathrm{P}_{0} \cdot\left(\frac{1}{16}\right)
$$

As geologists, we are interested in using these relationships to find the total time (t) since the start of a decay process. To do so we start with a simple rearrangement of equation (20):

$$
\left(\frac{\mathrm{P}_{\mathrm{n}}}{\mathrm{P}_{0}}\right)=\mathrm{k}^{\mathrm{n}} .
$$

Taking the logarithm of both sides of the equation and using the identity $\ln \left(\mathbf{a}^{\mathbf{b}}\right)=\mathbf{b} \ln \mathbf{a}$ we have: 


$$
\ln \left(\frac{\mathrm{P}_{\mathrm{n}}}{\mathrm{P}_{0}}\right)=\mathrm{n} \cdot \ln (\mathrm{k}) .
$$

The total time $\mathbf{t}(\mathrm{yr})$ is related to the number of units of time $\mathbf{n}$ and the length of one unit of time $\mathbf{t}_{\mathbf{k}}(\mathrm{yr})$ as follows:

$$
\mathrm{t}=\mathrm{n} \cdot \mathrm{t}_{\mathrm{k}} \text {. }
$$

Substituting for $\mathbf{n}$ in (23) using the relationship (24) and rearranging:

$$
\ln \left(\frac{\mathrm{P}_{\mathrm{n}}}{\mathrm{P}_{0}}\right)=\left[\frac{\mathrm{t}}{\mathrm{t}_{\mathrm{k}}}\right] \cdot \ln (\mathrm{k})=\mathrm{t} \cdot\left[\frac{\ln (\mathrm{k})}{\mathrm{t}_{\mathrm{k}}}\right] .
$$

It has been shown experimentally that, for any one radioactive isotope, the term in brackets on the right of (25) has the same value whatever unit of time $\left(\mathbf{t}_{\mathbf{k}}\right)$ is selected. This value is used to define a "decay constant" $(\lambda)$ :

$$
\lambda \equiv-\left[\frac{\ln (\mathrm{k})}{\mathrm{t}_{\mathrm{k}}}\right]
$$

where $\lambda$ is a positive number that has units of $(\mathrm{yr})^{-1}$. The minus sign is used because $\mathbf{k}$ is a fraction and, therefore, $\ln (\mathbf{k})$ is negative. Using (26) to substitute for the term in brackets in (25) and changing notation $\left(\mathbf{P}_{\mathbf{t}}=\mathbf{P}_{\mathbf{n}}\right.$, where $\mathbf{P}_{\mathbf{t}}$ is the number parent atoms remaining at time $\left.\mathbf{t}\right)$ we have:

$$
\ln \left(\frac{\mathrm{P}_{\mathrm{t}}}{\mathrm{P}_{0}}\right)=\mathrm{t} \cdot[-\lambda] .
$$

Rearranging (27) to solve for $\mathbf{t}$, we obtain:

$$
\mathrm{t}=-\frac{1}{\lambda} \ln \left(\frac{\mathrm{P}_{\mathrm{t}}}{\mathrm{P}_{0}}\right)=\frac{1}{\lambda} \ln \left(\frac{\mathrm{P}_{0}}{\mathrm{P}_{\mathrm{t}}}\right),
$$

which is the result we have been seeking. In these expressions, $\mathbf{P}_{\mathbf{0}}$ is the number parent atoms at time $\mathbf{t}=\mathbf{0}, \mathbf{P}_{\mathbf{t}}$ is the number parent atoms remaining at time $\mathbf{t}(\mathrm{yr})$, and $\boldsymbol{\lambda}\left(\mathrm{yr}^{-1}\right)$ is the decay constant. 
Our derivation of (28) assumes that $\mathbf{t} / \mathbf{t}_{\mathbf{k}}$ is an integer $\mathbf{n}$. This will not be correct for most times

(t) if the value of $\mathbf{k}$ is a large fraction (e.g. 1/2) or randomly chosen. However, because the unit of time $\mathbf{t}_{\mathbf{k}}$ is of arbitrary size, we can always choose the value $\mathbf{t}_{\mathbf{k}}$ so that $\mathbf{t} / \mathbf{t}_{\mathbf{k}}$ is an integer. Therefore, equation (28) is true for all cases and, indeed, is the same as the exact solution obtained using calculus to solve the differential equation

$$
\frac{\mathrm{dP}}{\mathrm{dt}}=-\lambda \mathrm{P}
$$

that expresses, for a continuous dynamic system, the experimental observation we used to obtain (15).

\section{Discussion}

It has been my observation that students remember more about their hands-on experiences in classes, labs, and field trips than about my lectures to them, and this trait has apparently been true for Smith College students for a long time (Blakeslee, 1945). In this paper, I have compiled information about a number of hands-on laboratory experiments that I have found to be useful in teaching about exponential decay and radiometric dating. Any one of these experiments might be used if the teaching goal is simply to provide a physical analog to help students understand the mathematics of radiometric dating. Using several of the experiments together has the added benefit of making connections for your students among a number of physical processes they should know about as geologists.

Throughout this paper I have emphasized the practical details of the decay experiments, providing advice on design and expected results (see Table 1 for observed half-lives). The learning that will result from adding these hands-on activities to your course depends on the classroom culture you create and the questions you ask. Don't give the students too much information; they will learn less if they are simply following your instructions. If you can divide 
the class into small groups, use some experiments that follow the exponential decay equation and others that do not. Challenge your students to prove the mathematical nature of the decay process they observe with graphical analysis. Have student groups trade experiments and apply or test each other's interpretation. Consider adding a mystery component such as finding the starting time of an already running experiment (e.g. Wise, 1990; AAAS Science Netlinks, 2001b; Sunderman, 2007). When did the vessel start draining? When will the vessel be empty? When will the coffee be cool enough to drink? When was the cup of coffee poured? What information or assumptions are needed to answer these questions? Ask students to explain deviations from their predictions and then design tests of their explanations. Insist that uncertainties in data collection and manipulation are evaluated and considered. Give the students enough time and motivation to do a good job. Have fun!

The skills students need for these experiments are ones that every scientist needs, including problem definition, thoughtful planning, careful lab work, good record keeping, appropriate mathematical analysis, critical thinking and interpretation, clear and complete written presentation of results. I believe this group of experiments is especially good for helping students reinforce or build their quantitative skills. The fact that a similar mathematical analysis can be applied to the many different processes emphasizes for students the utility of understanding exponential decay - and growth. Perhaps that knowledge will help them meet the challenges they face in a world where exponential growth of population and resource consumption continues, in spite of good advice to the contrary (Bartlett, 1978). It may also help them appreciate logistic (or sigmoid) functions, which have been used by Hubbard and others to understand the consumption of finite resources and concepts such as "peak oil" (Hubbard, 1971; Deffeyes, K.S., 2003).

The flows of water, heat, electricity, and atoms (by diffusion) are processes that can be described by similar differential equations. If the physical conditions are appropriate, the solutions to those 
equations are similar exponential decay equations like (28). This feature of these flows makes the experiments discussed here possible and, therefore, provides a possible starting point for more detailed consideration of those processes. In particular, if the boundary conditions do not represent flow between homogenous regions, other approaches are necessary to get solutions. The concepts and results of the analog experiments can be used to discuss and develop numerical, finite difference solutions for more complicated physical situations. Next steps could be simply mathematical, or they could be more experiments that use many vessels (e.g. Gilbert, 1979; Blanck and Gonnella, 2005) or circuits (Lawrence, 1970; Wunderlich and Peastrel, 1978). Alternatively, they could be to explore the underlying atomistic basis for the observed physics and the associated mathematics of probability and stochastic systems.

\section{Acknowledgements}

First, I must thank the many Smith College geology students who have shared decay adventures with me, leading I hope to their own growth. Traci Kuratomi and Greg Young built the U-tube, and Traci did a number of important experiments to calibrate the apparatus. I wish also to thank the friends and colleagues who have listened patiently, then offered advice as I discussed the latest experiment or result, including Jack Cheney, Jim Callahan, David Cohen, Elizabeth Denne, Nalini Easwar, Gary Felder, Mary Murphy, Robert Newton, Jurek Pfabe, and Malgorzata Pfabe. The non-calculus development of the decay equation is modified from a handout I was given in an introductory geology class in 1967-68 (taught by Steve Norton, Ray Siever, Bernie Kummel,

and Steve Gould). I have not been able to identify the author of the handout. Finally, I am very grateful for Len Vacher's thorough and thoughtful review, which led to many improvements in the final paper. 


\section{References}

AAAS Science Netlinks, 2001a, Radioactive decay: a sweet simulation of a half-life, http://www.sciencenetlinks.com/lessons.cfm?DocID=178 (22 Dec 2008).

AAAS Science Netlinks, 2001b, Frosty the snowman meets his demise: an analogy to carbon dating, http://www.sciencenetlinks.com/lessons.cfm?DocID=171 (22 Dec 2008).

Ansaldo, E.J., 1982, On Bernoulli, Torricelli, and the siphon, The Physics Teacher, v. 20, p. 243 244.

Barnet, J.E., 1998, Time's pendulum: the quest to capture time - from sundials to atomic clocks, New York, Plenum Trade, 340 p.

Bartlett, A.A., 1978, Forgotten fundamentals of the energy crisis, American Journal of Physics, v. 46, p. $876-888$.

Benimoff, A.I., 1999, A simulation of radioactive decay using dice; a comparison of exponential and probabilistic results [abstract], Geological Society of America Abstracts with Programs, v. 31, p. 4.

Blakeslee, A.F., 1945, Teachers talk too much: A taste demonstration vs. a talk about it, The American Biology Teacher, v. 7, 136-140.

Blanck, T.P., and Gonnella, H.F., 2005, A device to emulate diffusion and thermal conductivity using water flow, Journal of Chemical Education, v. 82, p. 1523-1529.

Bohn, J.L., and Nadig, F.H., 1938, Hydrodynamic model for demonstrations in radioactivity, American Journal of Physics, v. 6, p. 320-323.

Celnikier, L.M., 1980, Teaching the principles of radioactive dating and population growth without calculus, American Journal of Physics, v. 48, p. 211-213.

Dennis, C.M., Jr., 1980, Newton's law of cooling or is ten minutes enough time for a coffee break? The Physics Teacher, v. 18, p. 532-533.

Dewdney, J.W., 1959, Newton's law of cooling as a laboratory introduction to exponential decay functions, American Journal of Physics, v. 27, p. 668-669. 
Driver, R.D., 1998, Torricelli's law: An ideal example of an elementary ODE, The American Mathematical Monthly, v. 105, p. 453-455.

Fairman, S.J., Johnson, J.A., and Walkiewicz, T.A., 2003, Fluid flow with Logger Pro, The Physics Teacher, v. 41, p. 345-350.

Farmer, T., and Gass, F., 1992, Physical demonstrations in the calculus classroom, The College Mathematics Journal, v. 23, p. 146-148.

Fetter, C.W., 2001, Applied Hydrogeology, (4th Edition), Upper Saddle River, NJ, Prentice Hall, $598 \mathrm{p}$.

Gardner, C., Pyrtle, A.J., Greely, T., and Ivey, S., 2005, Half-life and spontaneous decay in the classroom [abstract], Geological Society of America Abstracts with Programs, v. 37, p. 152.

Gilbert, R., 1979, The diffusion simulator - teaching geomorphic and geologic problems visually, Journal of Geological Education, v. 27, p. 122-124.

Greenslade, T.B., Jr., 1994, The coffee and cream problem, The Physics Teacher, v. 32, 145-147.

Greenslade, T.B., Jr., 2002, Simulated secular equilibrium, The Physics Teacher, v. 40, 21-23.

Groetsch, C.W., 1993, Inverse problems and Torricelli's law, The College Mathematics Journal, v. 24, p. $210-217$.

Grossman, M.C., Shapiro, I.I., and Ward, R.B., 2000, Exploring time: sundials, water clocks, and pendulums: science journal, Watertown, MA, Charlesbridge, $73 \mathrm{p}$.

Guenther, W.C., 1958, Radioactive decay calculations without calculus, Journal of Chemical Education, v. 35, p. 414-415.

Deffeyes, K.S., 2003, Hubbert's Peak: The Impending World Oil Shortage (Paperback), Princeton University Press, 224p.

Hubbert, M.K., 1971, The energy resources of the earth, Scientific American, v. 225(3), p. 3140.

Huestis, S.P., 2002, Understanding the origin and meaning of the radioactive decay equation, Journal of Geoscience Education, v. 50, p. 524-527. 
Jones, W.H., 1957, A demonstration of rapid radioactive decay, Journal of Chemical Education, v. 34, p. 406-407.

Knauss, H.P., 1954, Hydrodynamic models of radioactive decay, American Journal of Physics, v. 22, p. $130-131$.

Lawrence, C.R., 1970, The resistor-capacitor electric analog model as an aid to the analysis of groundwater problems, Mining and Geological Journal, v. 6, p. 91-95.

Kowalski, L., 1981, Simulating radioactive decay with dice, The Physics Teacher, v. 19, p. 113.

McGeachy, F., 1988, Radioactive-decay - an analog, The Physics Teacher, v. 26, p. 28-29.

Mills, A.A., 1982, Newton's water clocks and the fluid mechanics of clepsydrae, Notes and Records of the Royal Society of London, v. 37, p. 35-61.

Moneychimp (2008) Compound interest (future value), http://www.moneychimp.com/articles/finworks/fmfutval.htm (22 Dec 2008).

National Geographic Kids, 2008, Water clock, http://www.nationalgeographic.com/ngkids/trythis/try10.html (29 May 2008).

Pierce, R. (2007) Compound interest - periodic compounding, http://www.mathsisfun.com/money/compound-interest-periodic.html (22 Dec 2008).

Priest, J., and Poth, J., 1983, Demonstrations for teaching nuclear energy, American Journal of Physics, v. 51, p. 185-187.

Rees, W.G., and Viney, C., 1988, On cooling tea and coffee, American Journal of Physics, v. 56, p. 434-437.

Schultz, E., 1997, Dice-shaking as an analogy for radioactive decay and first-order kinetics, Journal of Chemical Education, v. 74, p. 505-507.

Science Museum, 2008, Early Egyptian water clock, 1415-1380 BC, http://www.sciencemuseum.org.uk/images/I012/10326214.aspx (29 May 2008).

Shaw, C.H., and Saunders, N.,1955, Intermediate laboratory experiment in heat conduction, American Journal of Physics, v. 23, p. 89-90. 
Shea, J.H., 2001, Teaching the mathematics of radiometric dating, Journal of Geoscience Education, v. 49, p. 22-25.

Skinner, S.B., 1971, A simple experiment to illustrate exponential decay, half-life, and time constant, The Physics Teacher, v. 9, p. 269-270.

Sloley, R.W., 1931, Primitive methods of measuring time, Journal of Egyptian Archeology, v. 17, p. $166-178$.

Smith, S., 2008, Coffee cools more quickly if you wait to add the cream, http://www.eweek.org/site/news/Features/coffee.shtml (29 May 2008).

Smithson, J.R., and Pinkston, E.R., 1960, Half-life of a water column as a laboratory exercise in exponential decay, American Journal of Physics, v. 28, p. 740-742.

Sunderman, R., 2007, What time did the potato die?, http://serc.carleton.edu/sp/ssac home/general/examples/17797.html (22 Dec 2008).

Supon, F.W., and Kraushaar, J.J., 1983, Radioactive half-life measurements in a freshman or sophomore laboratory, American Journal of Physics, v. 51, p. 761-763.

Tyburczy, J.A., 2000, Heads or tails; a learning cycle exercise on radioactive decay and age determination, Journal of Geoscience Education, v. 48, p. 585-586.

Vacher, H.L., 2000, Computational Geology 9 - the exponential function, Journal of Geoscience Education, v. 48, p. 70-76.

Walker, J., 1977, Wonders of physics that can be found in a cup of coffee, Scientific American, v. 237, no. 5 , p. 152 .

Wenner, J.N. (2008a) Demonstration of radioactive decay using pennies, http://serc.carleton.edu/quantskills/activities/PennyDecay.html (22 Dec 2008).

Wenner, J.N. (2008b) M\&M model for radioactive decay, http://serc.carleton.edu/quantskills/activities/MandMModel.html (22 Dec 2008).

Wenner, J.N. (2008c) Using popcorn to simulate radioactive decay, http://serc.carleton.edu/quantskills/activities/popcorn.html (22 Dec 2008). 
Whyte, G.N., and Taylor, H.W., 1962, A radioactivity experiment using activities filtered from the air, American Journal of Physics, v. 30, p. 120-124.

Wise, D.U., 1990, Using melting ice to teach radiometric dating, Journal of Geological Education, v. 38, p. 38-40.

Wunderlich, F.J., and Peastrel, M., 1978, Electronic analog of radioactive decay, American Journal of Physics, v. 46, p. 189-190.

Zubrowski, B., 1988, Clocks: Building and Experimenting with Model Timepieces, Beech Tree Books, New York, 112 p. 


\begin{tabular}{|llc|}
\hline Experiment & Equipment & $\begin{array}{c}\text { 1st Half-life } \\
\text { (Minutes) }\end{array}$ \\
\hline U-Tube Water Flow & Two Plexiglass tubes, 1.75-inch i.d. \\
& $\begin{array}{l}\text { Copper connecting tube, 0.5-inch i.d. } \\
\text { Ball valve, 3/8-inch }\end{array}$ & \\
\hline Siphon Water Flow & Plastic tubing, 2 mm i.d., 4 feet long & $0.3-67.4$ \\
& Connecting two vertical tubes, 1.75-inch i.d. & 13 \\
\hline Cylindrical Tank Draining & Tennis ball tube, 6.5-inch high, 3/32-inch hole & 1.3 \\
& Tennis ball tube, 6.5-inch high, pin hole & 17 \\
\hline Coffee Cooling & Ceramic cup, 12-ounce, uncovered & 25 \\
& Paper cup, 12-ounce, uncovered & 28 \\
& Ceramic cup, 12-ounce, covered & 54 \\
& Paper cup, 12-ounce, covered & 54 \\
\hline Metal Cylinder Cooling & Al cylinder, 1.5-inch o.d., 3-inch long & 20 \\
\hline Capacitor Discharge & 0.47 farad, across 335 ohm resistor & 2 \\
& 1 farad, across 500 ohm resistor & 6 \\
\hline
\end{tabular}

Table 1. Observed half-lives of decay experiments. 

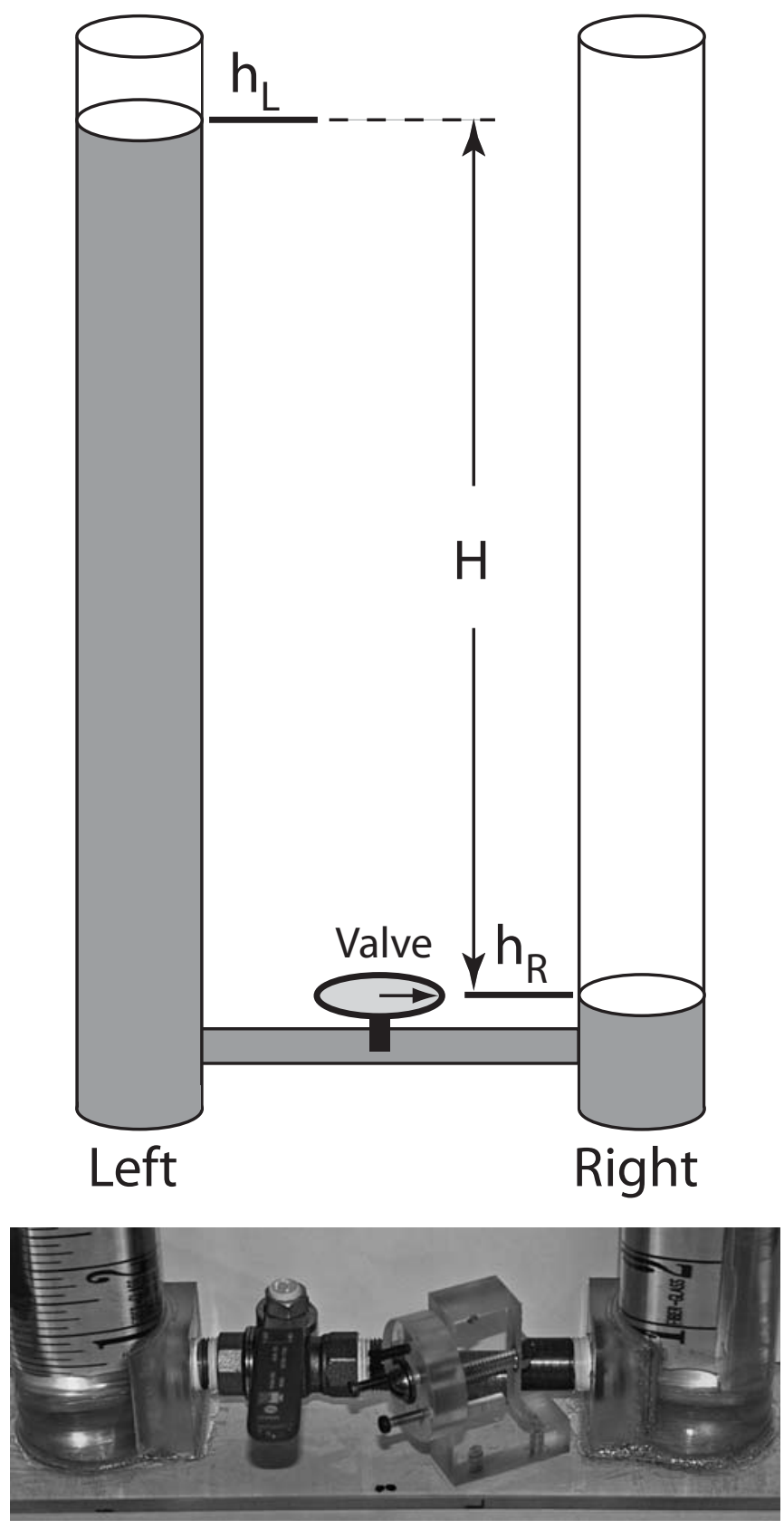

Figure 1. A schematic drawing of a "U-tube" apparatus, consisting of two vertical plastic tubes connected by a horizontal tube with a valve. The tube at the left is filled with water to height $\mathbf{h}_{\mathbf{L}}$; the tube at the right is filled with water to the height $\mathbf{h}_{\mathbf{R}}$. If the valve is opened, water will flow from the tube on the left to the tube on the right at a rate that is proportional to the difference in heights $\mathbf{H}$. The inset photo is a close-up view of the valve and setscrew mechanism to preset three valve positions and, therefore, flow rates. 


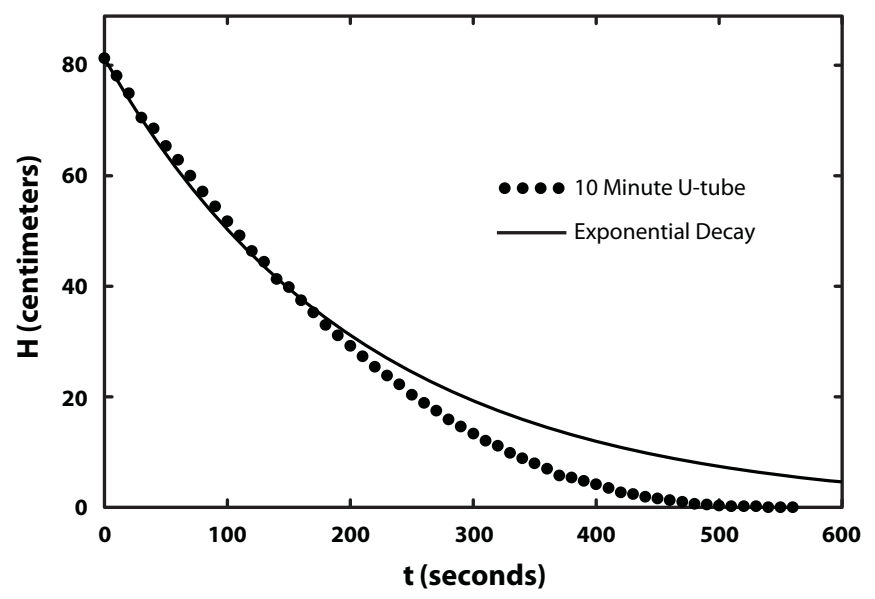

Figure 2. Data from a 10-minute-long U-tube experiment are shown in terms of the height difference $\mathbf{H}$ and time $\mathbf{t}$. Ideal exponential decay is shown as a solid curve using the experimental time for $\mathbf{H}$ to fall to half its starting value (144 seconds for this experiment) to define the half-life length. Note that the second and subsequent half-lives of the siphon experiment are shorter than the first half-life. 


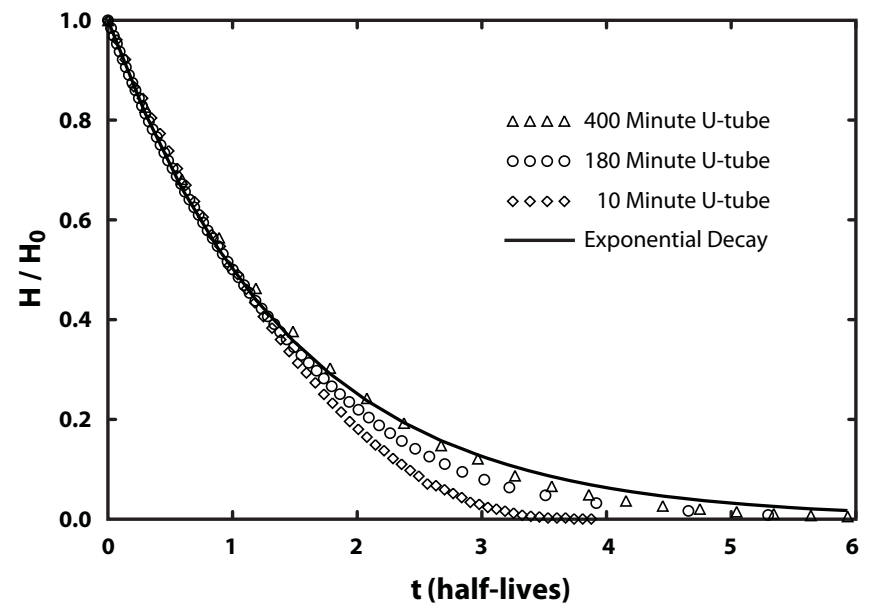

Figure 3. Data from three U-tube experiments are shown in terms of the fraction $\mathbf{H} / \mathbf{H}_{\mathbf{0}}$ of the original height difference $\mathbf{H}_{\mathbf{0}}$ and time $\mathbf{t}$ given as "half-lives", using the experimental time for $\mathbf{H} / \mathbf{H}_{\mathbf{0}}$ to fall to 0.5 to define the half-life length for each experiment. Ideal exponential decay is shown as a solid curve. Longer siphon experiments with slower flow rates more nearly approximate ideal exponential decay. 


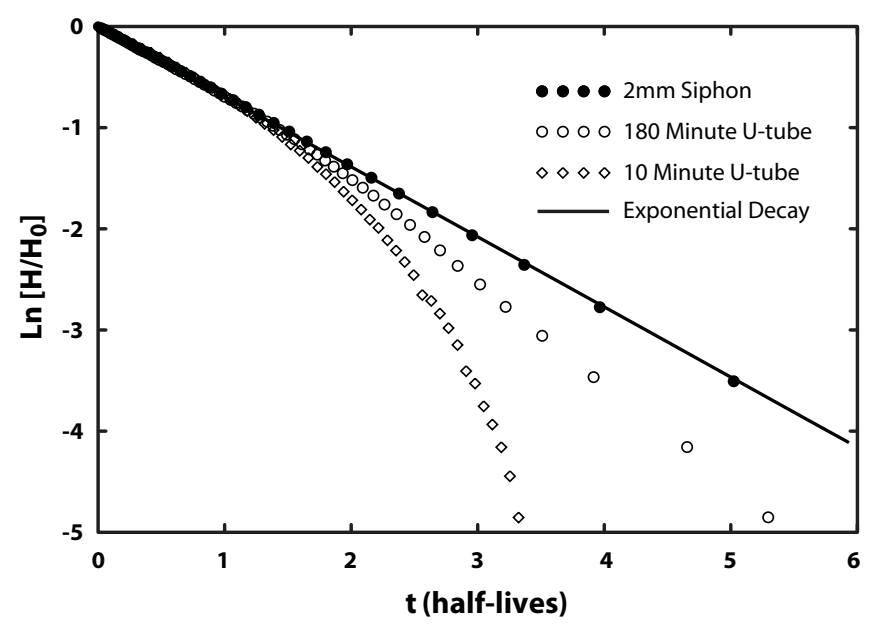

Figure 4. Data from a siphon experiment using a $2 \mathrm{~mm}$ i.d. siphon are shown in terms of the natural $\log$ of the fraction $\mathbf{H} / \mathbf{H}_{\mathbf{0}}$ of the original height difference $\mathbf{H}_{\mathbf{0}}$ and time $\mathbf{t}$ given as "halflives", using the first experimental half-life to normalize the data. Ideal exponential decay is shown as a solid straight line. Also shown for comparison are U-tube experimental data from Figure 3. The siphon data follow an exponential decay trend very closely when a "capillarysized" siphon is used. 
Brady: Exponential Decay

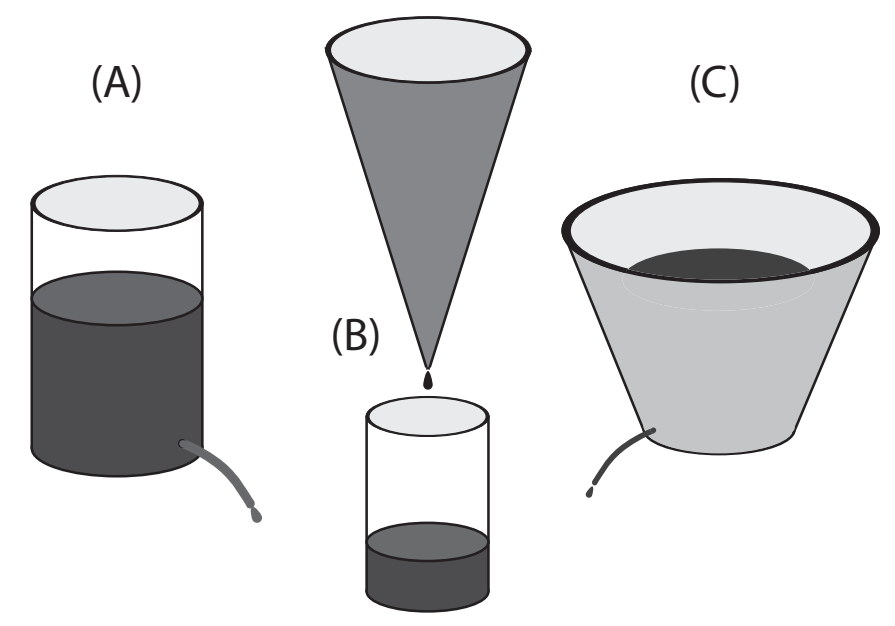

Figure 5. Drawings of water clock designs discussed in the text. (A) A cylinder with a hole near the bottom. (B) A cone with a hole at the bottom and water draining into a cylindrical collection vessel. (C) A bucket-shaped water clock with a bottom that is one-half the diameter of the top. 


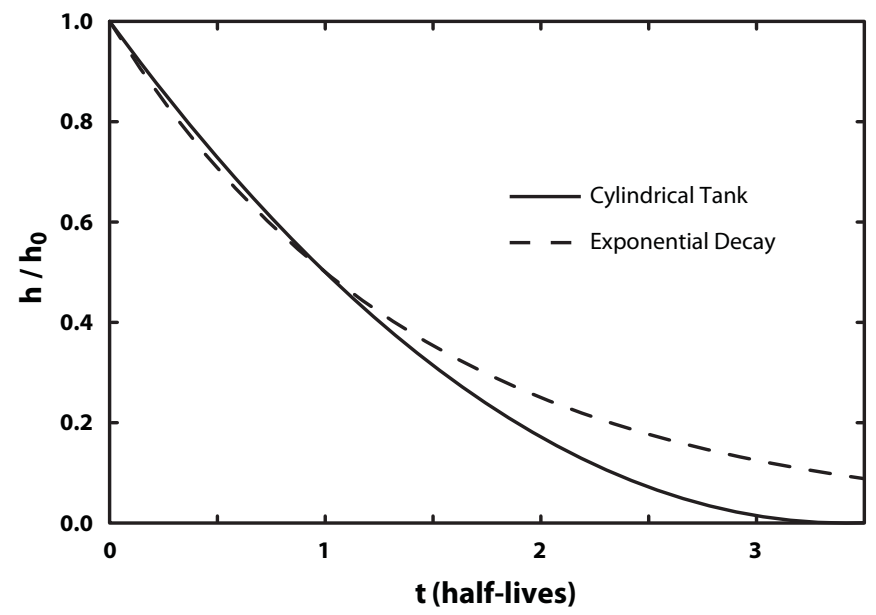

Figure 6 . Height of the water $\mathbf{h}$ in a cylindrical tank that is leaking from a hole near the bottom (Figure 5A) shown as a function of time $\mathbf{t}$. The height $\mathbf{h}$ is given as a fraction $\mathbf{h} / \mathbf{h}_{\mathbf{0}}$ of the starting height $\mathbf{h}_{\mathbf{0}}$ and the time $\mathbf{t}$ is given in units of half-lives, using the time for the water level to fall to one-half the original height to define the half-life. Ideal exponential decay is shown as a dashed curve. Neither the leaking tank nor exponential decay exhibits linear variation of water height with time, especially after the first half-life. 


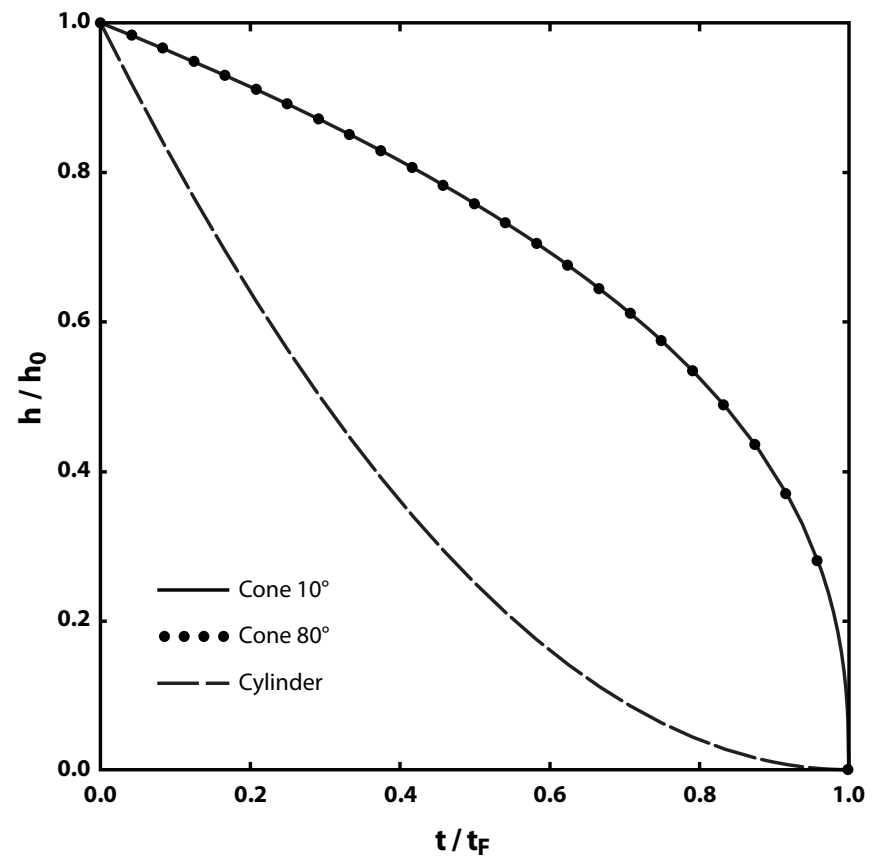

Figure 7. Height of the water $\mathbf{h}$ in a cone-shaped water clock (Figure 5B) that is leaking from a hole at the bottom of the cone shown as a function of time $\mathbf{t}$. The height $\mathbf{h}$ is given as a fraction $\mathbf{h} / \mathbf{h}_{\mathbf{0}}$ of the starting height $\mathbf{h}_{\mathbf{0}}$ and the time $\mathbf{t}$ is given as a fraction $\mathbf{t} / \mathbf{t}_{\mathbf{F}}$ of the total time $\mathbf{t}_{\mathbf{F}}$ needed to drain the water clock. Calculated results for cone-shaped water clocks with very different cone angles $\left(10^{\circ}\right.$ and $\left.80^{\circ}\right)$ are identical when normalized in this way. Also shown for comparison is the time variation of the water height in a cylindrical water clock (Figure 5A). 


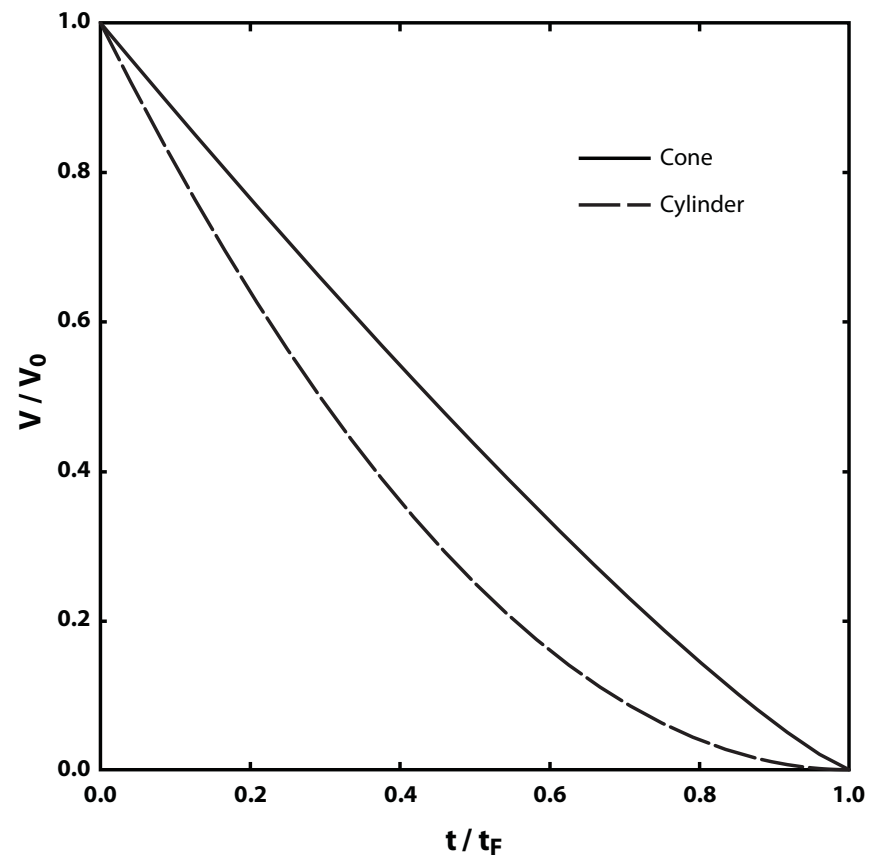

Figure 8. Volume of the water $\mathbf{V}$ of the water in a cone-shaped water clock (Figure 5B) that is dripping from a hole at the bottom of the cone shown as a function of time $\mathbf{t}$. The volume $\mathbf{V}$ is given as a fraction $\mathbf{V} / \mathbf{V}_{\mathbf{0}}$ of the starting volume $\mathbf{V}_{\mathbf{0}}$ and the time $\mathbf{t}$ is given as a fraction $\mathbf{t} / \mathbf{t}_{\mathbf{F}}$ of the total time $\mathbf{t}_{\mathbf{F}}$ needed to drain the water clock. Also shown for comparison is the time variation of the volume of water in a cylindrical water clock (Figure 5A). The volume of water released from the cone-shaped water clock exhibits a nearly linear variation with time over a large fraction of the time needed to drain the clock. Therefore, the height of water in a cylindrical collection vessel would rise uniformly with time. 


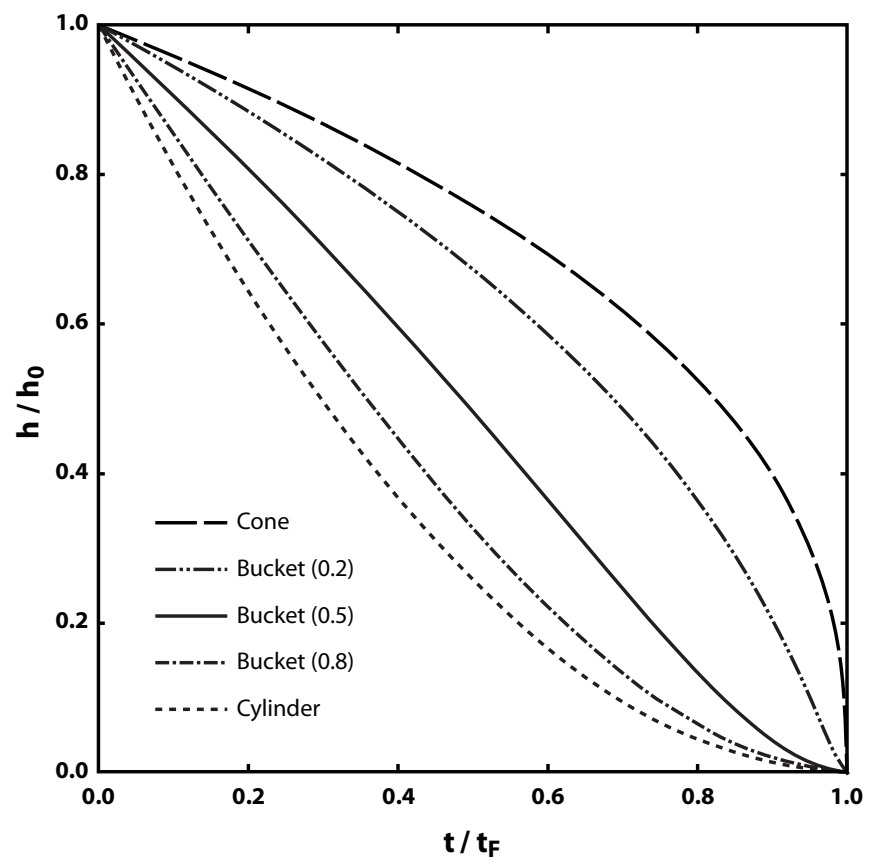

Figure 9. Height of the water $\mathbf{h}$ in a bucket-shaped water clock (Figure 5C) that is leaking from a hole at the bottom of the bucket is shown as a function of time $\mathbf{t}$. The height $\mathbf{h}$ is given as a fraction $\mathbf{h} / \mathbf{h}_{\mathbf{0}}$ of the starting height $\mathbf{h}_{\mathbf{0}}$ and the time $\mathbf{t}$ is given as a fraction $\mathbf{t} / \mathbf{t}_{\mathbf{F}}$ of the total time $\mathbf{t}_{\mathbf{F}}$ needed to drain the water clock. Calculated results for bucket-shaped water clocks with bottoms that are different fractions of the height of a cone are shown. The height of the water in a bucket-shaped water clock that has a bottom at 0.5 exhibits a nearly linear variation with time over a large fraction of the time needed to drain the clock. Also shown for comparison is the time variation of the water height in a cylindrical water clock (Figure 5A) and a cone-shaped water clock (Figure 5B). 


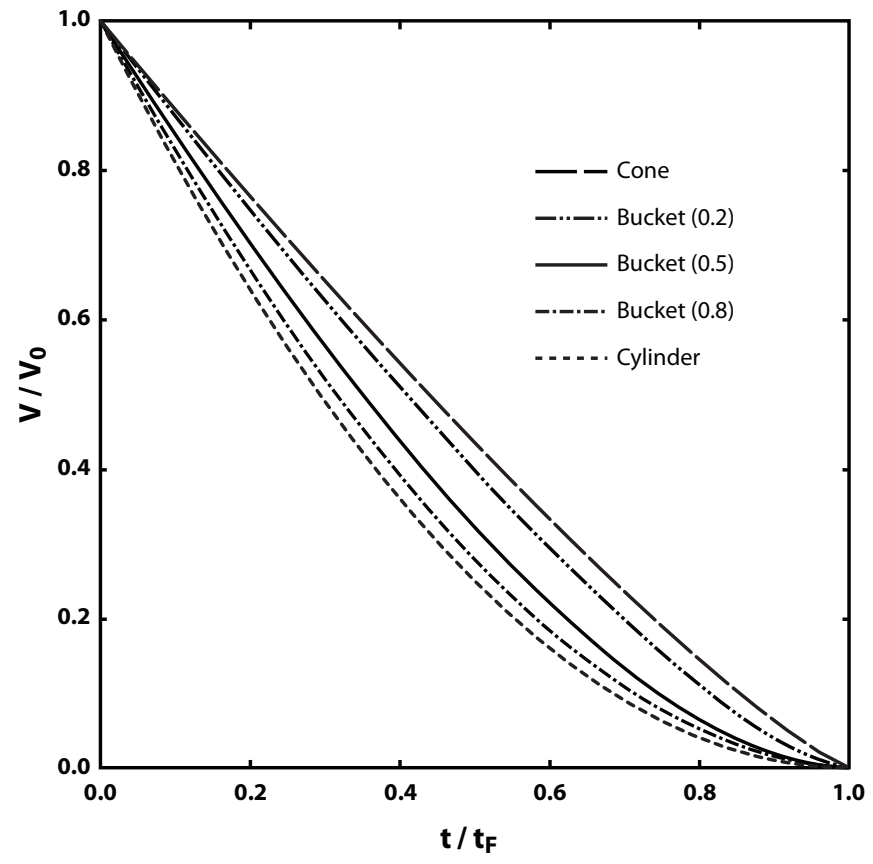

Figure 10. Volume of the water $\mathbf{V}$ in a bucket-shaped water clock (Figure 5C) that is leaking from a hole at the bottom of the bucket shown as a function of time $\mathbf{t}$. The volume $\mathbf{V}$ is given as a fraction $\mathbf{V} / \mathbf{V}_{\mathbf{0}}$ of the starting volume $\mathbf{V}_{\mathbf{0}}$ and the time $\mathbf{t}$ is given as a fraction $\mathbf{t} / \mathbf{t}_{\mathbf{F}}$ of the total time $\mathbf{t}_{\mathbf{F}}$ needed to drain the water clock. Calculated results for bucket-shaped water clocks with bottoms that are different fractions of the height of a cone are shown. Also shown for comparison are the time variations of the volume of water in a cylindrical water clock (Figure 5A) and a cone-shaped water clock (Figure 5B). Of these water clocks, the rate of water release from the cone-shaped clock is the most uniform with time. 


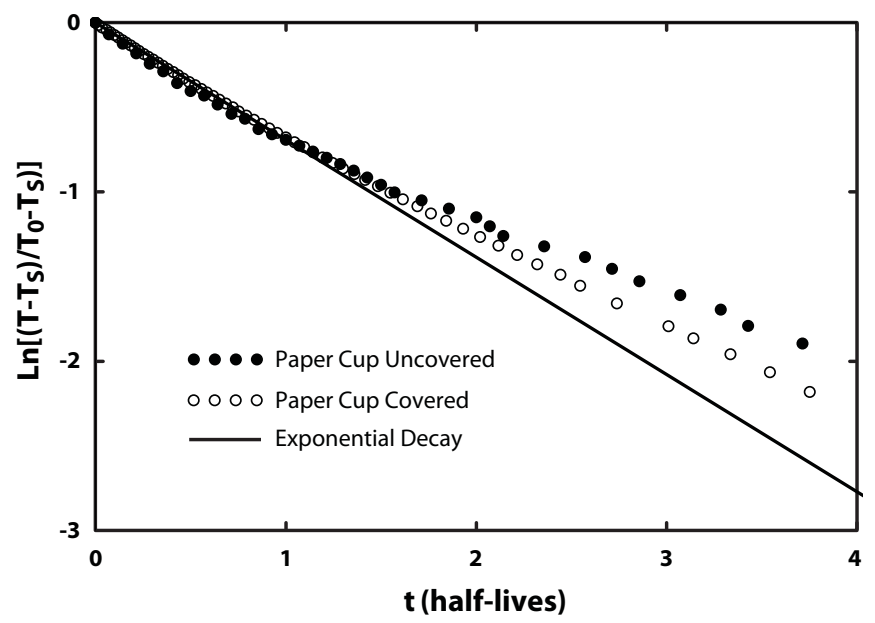

Figure 11. Experimental data for cooling coffee in 12-ounce paper cups, uncovered and covered. The logarithm of the fractional difference between the temperature of the coffee $\mathbf{T}$ and the temperature of the surroundings $\mathbf{T}_{\mathbf{S}}$ is shown in terms of time given in cooling half-lives. $\mathbf{T}_{\mathbf{0}}$ is the measured temperature of the coffee when the cooling started (uncovered $82^{\circ} \mathrm{C}$, covered $\left.92^{\circ} \mathrm{C}\right)$. The data for the two experiments were normalized based on their own temperatures and first half-lives (uncovered 28 minutes, covered 54 minutes). The covered cup data more closely approach exponential cooling, which is shown by the straight line. 
Brady: Exponential Decay

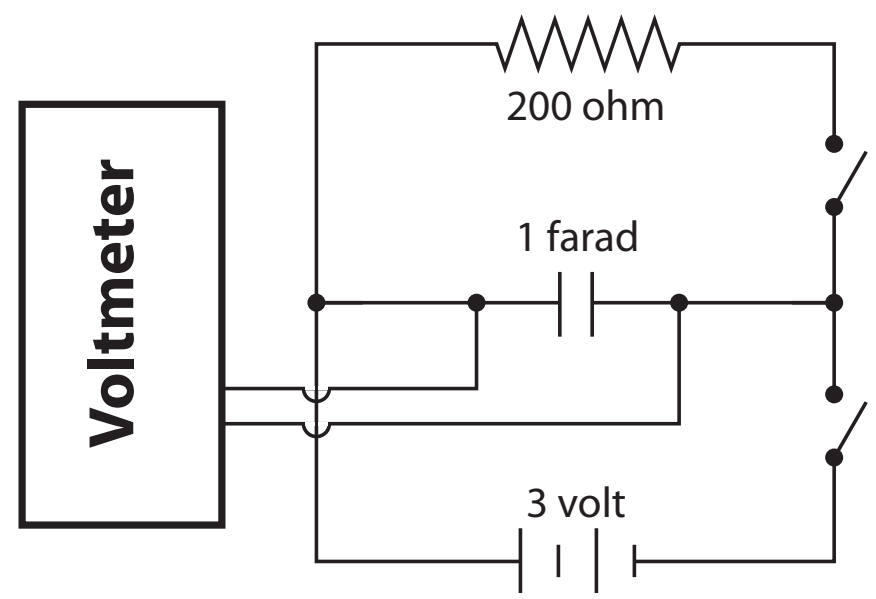

Figure 12. Circuit diagram for a simple capacitor discharge experiment. Two D batteries in series are used to charge the capacitor by closing the bottom switch. The capacitor is discharged by opening the lower switch and closing the upper switch. As noted in the text, the voltage of the capacitor will decrease exponentially with time and can be monitored with the voltmeter. 